Received: 3 October 2020 Accepted: 14 November 2020

DOI: https://doi.org/10.33182/bc.v10i2.1161

\title{
Household food insecurity and associated socio-economic factors among recent Syrian refugees in two Canadian cities
}

\author{
Lina Al-Kharabsheh ${ }^{1}$, Samer Al-Bazz ${ }^{2}$, Mustafa Koc ${ }^{3}$, Joe Garcia ${ }^{4}$, Ginny Lane ${ }^{5}$, Rachel \\ Engler-Stringer ${ }^{6}$, Judy White ${ }^{7}$; Hassan Vatanparast ${ }^{8}$
}

\begin{abstract}
In Canada, the prevalence of food insecurity is high among low-income households, particularly recent refugees. We evaluated the prevalence of food security among recent Syrian refugees and the associated factors in two Canadian cities, Toronto and Saskatoon. We collected data using the Household Food Security Model, sociodemographic and socioeconomic questionnaires from 151 families. $84 \%$ of the Syrian households were food insecure, with no significant difference in prevalence between Saskatoon and Toronto. The risk of food insecurity was four times higher for households with the annual income below \$40,000. Households with educated woman (high school or higher) had four times higher risk of household food insecurity compared to families with less-educated women. Our findings indicate the high prevalence of food insecurity among recently resettled Syrian refugees in Canada. Higher-income directly associated with food security. The inverse association between education and food security in households with highly educated women warrants further investigation.
\end{abstract}

Keywords: Syrian refugees; food security; income; education; resettlement countries.

\section{Introduction}

Several studies have highlighted the high prevalence of food insecurity among refugees in Canada and elsewhere in the world. War-torn Syria produced the highest number of refugees in 2015 and 2017, accounting for 4.1million, and 6.6 million refugees, respectively (UNHCR, 2018). In September 2015, as a recognition of the Syrian crisis, the Government of Canada, in collaboration with the United Nations High Commissioner for Refugees (UNHCR), prioritized the resettlement of most vulnerable Syrian refugees. In light of the criteria developed in the selection of Syrian refugees with higher needs, families with children and women at risk were prioritized (Immigration Refugees and Citizenship Canada, 2016). Syrian refugees in Canada arrived through three main

${ }^{1}$ Lina Al-Kharabsheh, College of Pharmacy and Nutrition, University of Saskatchewan, Saskatoon, SK, Canada. E-mail: Laa064@mail.usask.ca

2 Samer Al-Bazz, College of Pharmacy and Nutrition, University of Saskatchewan, Saskatoon, SK, Canada. E-mail: saa331@mail.usask.ca

${ }^{3}$ Mustafa Koc, Sociology, Ryerson University, Toronto, ON, Canada. E-mail: mkoc@ryerson.ca

${ }^{4}$ Joe Garcea, Political Studies, University of Saskatchewan, Saskatoon, SK, Canada. E-mail: joe.garcea@usask.ca

${ }^{5}$ Rachel Engler-Stringer, Community Health and Epidemiology, University of Saskatchewan, Saskatoon, SK, Canada. E-mail: rachel.engler-stringer@usask.ca

${ }^{6}$ Ginny Lane, School of Public Health, University of Saskatchewan, Saskatoon, SK, Canada. virginia.lane@usask.ca

${ }^{7}$ Judy White, Faculty of Social Science, University of Regina, Regina, SK, Canada. E-mail: judy.white@uregina.ca

${ }^{8}$ Hassan Vatanparast, College of Pharmacy and Nutrition and School of Public Health, University of Saskatchewan, Saskatoon, SK, Canada. E-mail: vatan.h@usask.ca 
sponsorship categories: Government-Assisted Refugees (GAR), Privately Sponsored Refugee (PSR), and Blended Visa Office-Referred Program (BVOR). ${ }^{9}$ Between late 2015 and early 2017, 40,081 Syrian refugees were resettled in 350 different Canadian communities (Immigration, Refugees and Citizenship Canada, 2017). About 12,378 and 1,188 refugees resided in Ontario and Saskatchewan, respectively (Government Canada, 2018). The high number Syrian refugees established a new record in Canada, resettling the highest number of refugees in nearly four decades in 2016. (Immigration, Refugees and Citizenship Canada, 2017).

Resettled Syrian refugees are granted permanent resident status (Canadian Council for Refugees, 2010) and have access to Canada's social, health, and integration services. However, the rapid influx of Syrian refugees raises concerns about the availability of adequate resettlement and integration resources and support. Syrian refugees continue to be in a disadvantaged situation after resettlement in Canada due to challenges related to varying education levels, low proficiency in official language, employment and income, affordable housing, accreditation of their work and education experience, social integration, and high medical needs (Immigration, Refugees and Citizenship Canada, 2016). In addition, compared to other refugee groups, Syrian refugees had both a higher proportion of families with children and a higher number of children in these families (Houle, 2019). Given these challenges, Syrian refugees may be vulnerable to low economic wellbeing, which might negatively impact adequate access to culturally appropriate food. Most research on the first wave of Syrian refugees in Canada focuses on their resettlement experience in Canadian society (Drolet et al., 2018; Drolet \& Moorthi, 2018; Fanget al., 2017). Less is known about food security status of Syrian refugees and its determinants in Canada.

Food insecurity is defined as "limited access to or availability of nutritionally-adequate, culturally- relevant, and safe food and/or limited or uncertain ability to acquire food in socially acceptable ways" (Food and Agriculture Organization of the United Nations, 1996). Food insecurity is known to have adverse effects on physical and mental health problems, nutritional vulnerabilities and, in some cases, mortality and increased healthcare costs (Men et al., 2020; Kirkpatrick, \& Tarasuk., 2008; Lee et al., 2019, Jessiman et al., 2017, Tarasuk et al., 2015). While food security is one of the social determinants of health, it is impacted by social determinants of health, such as employment, education, immigration status and income (Dietitians of Canada, 2016; Government of Canada, 2018). Notably, socioeconomically disadvantaged segments of the population are most vulnerable to food insecurity (Tarasuk et al., 2019).

In Canada, food insecurity is predominant among newcomer immigrants and refugees (Lane et al., 2019; Tarasuket al., 2016). The 2014 Canadian Community Health Survey (CCHS) reported that $15.2 \%$ of recent immigrants (less than five years) were food insecure, compared to $12 \%$ of longer-term immigrants and $11.8 \%$ of Canadian born respondents (Tarasuket al., 2016)According to these results, recent immigrants are more vulnerable to food insecurity; however, the CCHS surveys do not differentiate between refugees and immigrants in their analysis and exclude participants who cannot speak in English or French. This means excluding newcomers, particularly

\footnotetext{
${ }^{9}$ GAR's is for those no longer in their countries of origin and who, involuntarily, cannot return to their home country due to a fear of persecution. The Government of Canada or Quebec delivers this support through non-governmental agencies. Refugees under the PSR program, a private sponsor agrees to provide them with care, lodging, settlement assistance, and support. Nuanced variations exist, such as groups of individuals or church communities who collectively sponsor a refugee family. The BVOR program is a relatively new (as of 2013) that matches refugees identified for resettlement by the United Nations High Commissioner for Refugees (UNHCR) and who received resettlement assistance from both the federal government and private sponsors.
} 
refugees, since language barrier is one of the main challenges among newcomers. The study by Lane et al. (2019) revealed that refugees' food insecurity status was significantly different from that of immigrants. Refugees "who are forced to flee from their home country (Canadian Council for Refugees, 2010) tend to have fewer resources and opportunities compared to immigrants. According to Lane et al. (2019), around 55\% of recent refugee households in Saskatchewan were food insecure, compared to $43 \%$ of immigrant households. Various studies in Australia and the United States have observed a high prevalence of food insecurity among refugees to vary between $70 \%$ and 91\% (McKay et al., 2019; Nunnery \& Dharod, 2017), while approximately 63\% of Palestinian and $80 \%$ of Iraqi refugees in Lebanon are at increased risk of food insecurity (Ghattas, et al., 2014 and 2015). These studies point out that food insecurity is relatively common among refugees, even in high-income countries.

Given the limitations of previous studies, more research is required to assess the prevalence of food insecurity among recent Syrian refugees. This study will be the first, to our knowledge, to determine the household, adult and child food security status of Syrian refugees in Saskatoon and Toronto; explain the socio-economic status of Syrian refugees; explain the association between socio-economic status and food security, and compare food security levels of Syrian refugees with the Canadian population and immigrants.

\section{Materials and method}

\section{Study design and study population}

This cross-sectional study was performed in two Canadian metropolitan cities - Toronto, Ontario, and Saskatoon, Saskatchewan. These cities were selected due to their differences in population size, cultural diversity, social structure, and support systems, which may impact the determinants of food security. In past years, typically half of the recent immigrants settled in Toronto, Montreal and Vancouver; however, between 2011-2016, immigration to Saskatchewan increased by 97\%, more than any other Canadian jurisdiction (Statistics Canada, 2017).

Study respondents were adult members of Syrian refugee families who arrived after December 2015 and settled in Saskatoon and Toronto. To consider the difference in socio-demographic status of Syrian refugees among the three categories: Government-assisted Refugees (GAR), Private Sponsorship of Refugees (PSR), and Blended Visa Office-Referred program (BVOR) (Houle, 2019; Immigration Refugees and Citizenship Canada, 2016), purposeful sampling was used. The percentages of resettled Syrian refugee families by their immigration category in Ontario were 39 $\%$ (1,405 Families) GAR, 1\% (349 families) BVOR and 51 \% (1,826 families) PSR (2016). Whereas in Saskatchewan, distribution was as follows, 87\% (214 Families) GAR, 8.5\% (21 families) BVOR and 4\% (10 families) PSR (Immigration, Refugees and Citizenship Canada. (2016). On average, Syrian refugees who were under the GAR category were with a higher percentage of couples with children than those who were under the PSR category. In terms of socioeconomic characteristics, GAR had a lower level of education and lower levels of proficiency in the official languages as compared to PSR and other refugees from other countries (Houle, 2019). These findings are compatible with the vulnerability selection criteria that was mentioned earlier. Overall the 151 participants were from Government-assisted (GAR, $n=122$ ), privately-sponsored (PSR n=20), and blended visa office-referred (BVOR, $\mathrm{n}=8$ ) categories. Settlement agencies (i.e., Saskatoon Open Door Society, and in Toronto Poly cultural immigrant and community center, Muslim association 
of Canada, and the Arab community center of Toronto (both Scarborough and Mississauga locations), refugee associations and community members assisted with the recruitment of eligible participants. Arabic speaking Syrian community coordinators recruited families from the client database of the settlement organizations. The consent forms were provided in both English and Arabic languages and explained to the participants in Arabic language. The recruited respondents provided written consent and received an honorarium for participating in the study.

\section{Data Collection and Measures}

Data was collected between December 2016 and March 2017, through approximately one hour face to face interviews in the Arabic language by trained Arabic speaking research assistants. Data collection relied on two questionnaires: (1) Socio-demographic and economic characteristics, and (2) food security. Both questionnaires were translated into the Arabic language using common Syrian vocabulary and then tested for accuracy. Raw data was entered in the English language into REDCap, a secure research electronic data capturing application hosted at the University of Saskatchewan. This study protocol was approved by the University of Saskatchewan and Ryerson University Ethics Boards.

\section{Socio-demographics data collection}

The first questionnaire collected data on socio-demographic and economic characteristics of refugee household (e.g., age, sex, marital status, education, household income, the main source of income, duration of stay, official language proficiency, and the number of people in a household). The questions were adopted from the standard questionnaires used in the 2006 Canadian census (Statistics Canada, 2018) and the CCHS ( Statistics Canada, 2018). Questions were answered by either the primary breadwinner of the family or an adult who was older than 18 years.

\section{Foods security}

The second questionnaire measured income-related food security status using the Household Food Security Survey Module (HFSSM) that was developed by the U.S Department of Agriculture. The module was adopted and validated by Health Canada and has been used in the Canadian Community Health Survey (CCHS) since 2004 (Health Canada, 2012). The HFSSM contains 18 questions that reflect household experiences of food insecurity over the previous 12 months related to income constraints or lack of resources impeding adequate access to food. The questions in the module distinguish between the experiences of children and adults using a child scale and adult scale. The child scale consists of eight questions that are administered to households with children under 18 years to assess their experience of food insecurity, while the adult scale (10 questions) assesses the overall household situation and adults' specific experiences of food insecurity (Health Canada, 2012). The food security status of Syrian refugee households in Saskatoon and Toronto were determined at the household, adult and child levels. The HFSSM questions were to be preferably answered by the female head of the family, but that was not always possible as only one partner (man or woman) was able to participate in the survey.

We categorized household food security status based on the Food Insecurity Policy Research Project classification, developed by Tarasuk, Mitchell and Dachner (2016): (1) food security (no problems of food access, income-related or otherwise), (2) marginal food insecurity (some level of concern, or income-related barriers to adequate and secure food), (3) moderate food insecurity (lack 
of food or money producing a compromise in the quality/quantity of food), and (4) severe food insecurity (reduced food intake or interrupted eating patterns) (Tarasuk et al., 2016).

\section{Statistical Analysis}

Data were analyzed using SAS software (version 9.4) SAS Institute, Cary, North Carolina, United States. Descriptive statistics were used to characterize Syrian refugees' socio-economic characteristics and household food security status. The prevalence of food insecurity status across the three categories of Syrian refugee households was evaluated using the chi-square test. Due to low sample size and low frequency categories of food insecure households, households were classified as food secure or food insecure. Where the latter merged the marginal, moderate, and severe food insecure categories. Independent variables to evaluate in association with food insecurity were selected by referring to existing studies (Lane et al., 2019; McKay et al., 2019; Nunnery \& Dharod, 2017; Tarasuk et al., 2019; Vahabi et al., 2011). The categorical sociodemographic and economic variables included in this study were: sex (male, female), marital status (married, not married), woman's education (illiterate/primary, higher than primary education), income earner's education (illiterate/primary, higher than primary education), income $(<\$ 40,000$, $\geq \$ 40,000$ ), main income source (social welfare, other income sources except social welfare), language proficiency (poor/very poor, proficient/fluent), and household size (1-5, $\geq 6)$. After testing for collinearity, stepwise logistic regression was used to identify the factors associated with food insecurity.

\section{Results}

One hundred and fifty-one households participated in the study in Saskatoon $(\mathrm{n}=51)$ and Toronto $(\mathrm{n}=100)$. At the household level, overall, the prevalence of food insecurity was $84 \%$. Of those, approximately $12 \%$ experienced marginal food insecurity, $41 \%$ experienced moderate food insecurity, and $31 \%$ experienced severe food insecurity (Table 1).

Table 1 Food security status among Syrian refugees in Toronto and Saskatoon.

\begin{tabular}{lccccccccc}
\hline & \multicolumn{3}{c}{ Saskatoon $(\mathbf{n}=\mathbf{5 1})$} & \multicolumn{3}{c}{ Toronto $(\mathbf{n}=\mathbf{1 0 0})$} & \multicolumn{3}{c}{ Total $(\mathbf{n}=\mathbf{1 5 1})$} \\
& Children & Adult & Household & Children & Adult & Household & Children & Adult & Household \\
\hline $\begin{array}{l}\text { Food secure } \\
\text { (n, \%) }\end{array}$ & 10,22 & 5,10 & 4,8 & 25,26 & 33,33 & 19,20 & 35,25 & 38,25 & 23,16 \\
$\begin{array}{l}\text { Marginally Food } \\
\text { Insecure (n, \%) }\end{array}$ & 8,18 & 8,16 & 6,13 & 20,21 & 8,8 & 11,12 & 28,20 & 16,11 & 17,12 \\
$\begin{array}{l}\text { Moderately Food } \\
\text { Insecure (n, \%) }\end{array}$ & 17,38 & 18,36 & 17,35 & 40,43 & 38,38 & 41,43 & 57,41 & 56,37 & 58,41 \\
$\begin{array}{l}\text { Severely Food } \\
\text { Insecure (n, \%) }\end{array}$ & 10,22 & 19,38 & 21,44 & 8,9 & 21,21 & 24,25 & 18,13 & 40,27 & 45,31 \\
$\begin{array}{l}\text { Total Food } \\
\text { Insecure (n, \%) }\end{array}$ & 35,78 & 45,90 & 44,92 & 68,74 & 67,67 & 76,80 & 103,75 & 112,75 & 120,84 \\
\hline
\end{tabular}

*No significant differences observed.

No significant difference was found in food security status between families located in Saskatoon and Toronto. Table 2 displays selected socio-demographic and economic characteristics of food-secure and food-insecure households. The only significant finding is that $74.1 \%$ of foodinsecure households had an annual income of $\$ 40,000$ or less compared to $52.4 \%$ of the food securerespondents. 
As shown in Tables 2 and 3, around $3 / 4$ of the food insecure Syrian refugee households had an annual income below $\$ 40,000$, while only about $52.4 \%$ of food secure families were in this income category. Associations between socio-demographic factors and food insecurity are described in Table 4. A stepwise multiple logistic regression analysis was conducted with six variables, including sex, income decile, income earner education, woman's education, duration of stay and household size. Households with annual income above $\$ 40,000$ had a higher rate of food security. The risk of household food insecurity was about four times higher for households with an annual income of $\$ 40,000$ or less compared to those whose annual income was above $\$ 40,000$. In addition, households that included a woman who had completed high school or higher education were at four times higher risk for household food insecurity compared to families that included a woman with lower education.

Table 2. Socio-demographic characteristics of Syrian refugee participants among food secured and food insecure

\begin{tabular}{lcc}
\hline \multirow{2}{*}{ Socio-demographic Characteristics } & \multicolumn{2}{c}{ Total Population, N=151 } \\
& Food Insecure & Food Secure \\
\hline Mean age (+/- SD), years & $37.9(\mathrm{SD})$ & $40.0(\mathrm{SD})$ \\
Gender (\% Female) & 38.3 & 34.8 \\
Marital Status (\% Married) & 94.2 & 95.7 \\
Women Education (\%illiterate/primary) & 35.3 & 52.2 \\
Income Earner Education (\%illiterate/primary) & 37.6 & 21.7 \\
Income (Less than \$40,000) & $74.1^{*}$ & 52.4 \\
Main Income Source (\% Welfare) & 89.9 & 95.5 \\
Duration of Stay (\% more than a year) & 58.3 & 60.9 \\
Language Proficiency (\% Poor/Very Poor) & 68.9 & 65.2 \\
Household size (1-5) & 56.0 & 56.5 \\
\hline
\end{tabular}

${ }^{*}$ Significant at 0.05 level of significance using chi -squared test for categorical variables and t-test for continuous variables.

Table 3. Distribution of households' annual income among total Syrian refugee sample by food security status.

\begin{tabular}{lccc}
\hline Annual Income & Total population (\%) & $\begin{array}{c}\text { Food Insecure } \\
(\%)\end{array}$ & $\begin{array}{c}\text { Food Secure } \\
(\%)\end{array}$ \\
\hline$<\$ 5000$ & 14.7 & 14.8 & 14.3 \\
$\$ 5000-\$ 10000$ & 4.4 & 5.6 & 0.0 \\
$\$ 10000-\$ 15000$ & 5.9 & 3.7 & 9.5 \\
$\$ 15000-\$ 20000$ & 7.3 & 7.4 & 4.8 \\
$\$ 20000-\$ 25000$ & 4.4 & 4.6 & 0.0 \\
$\$ 25000-\$ 30000$ & 9.6 & 10.2 & 4.8 \\
$\$ 30000-\$ 40000$ & 25.7 & 27.8 & 19.0 \\
$\$ 40000-\$ 50000$ & 21.3 & 21.3 & 28.5 \\
$\$ 50000-\$ 60000$ & 6.0 & 4.6 & 14.3 \\
$\$ 60000-\$ 80000$ & 0.7 & 0.0 & 4.8 \\
Total & 100 & 100 & 100 \\
\hline
\end{tabular}

*No significant differences observed 
Table 4. Factors associated with the food security status of recent Syrian refugees in Canada

\begin{tabular}{|c|c|c|}
\hline \multirow[b]{2}{*}{ Socio-demographic variables } & \multicolumn{2}{|c|}{ Total Population, $\mathbf{N}=151$} \\
\hline & Odds Ratio & $95 \%$ CI \\
\hline \multicolumn{3}{|l|}{ Sex } \\
\hline Female $^{\mathrm{R}}$ & 1 & - \\
\hline Male & 0.7 & $(0.2-2.2)$ \\
\hline \multicolumn{3}{|l|}{ Income Decile } \\
\hline Decile $(8-10)$ or $(\text { income } \geq \$ 40000)^{R}$ & 1 & - \\
\hline Decile $(1-7)$ or $($ income $<\$ 40000)$ & $3.9^{*}$ & $(1.2-13.2)$ \\
\hline \multicolumn{3}{|l|}{ Women Education } \\
\hline Illiterate/Primary ${ }^{\mathrm{R}}$ & 1 & - \\
\hline High School or Higher & $4.3^{*}$ & $(1.4-13.3)$ \\
\hline \multicolumn{3}{|l|}{ Income Earner Education } \\
\hline Illiterate/Primary ${ }^{\mathrm{R}}$ & 1 & - \\
\hline High School or Higher Education & 0.3 & $(0.1-1.2)$ \\
\hline \multicolumn{3}{|l|}{ Duration of Stay } \\
\hline More than a Year ${ }^{R}$ & 1 & - \\
\hline Less than a Year & 1.1 & $(0.4-3.3)$ \\
\hline \multicolumn{3}{|l|}{ Household size } \\
\hline $1-5^{\mathrm{R}}$ & 1 & \\
\hline$\geq 6$ & 2.9 & $(0.9-10.0)$ \\
\hline
\end{tabular}

\section{Discussion}

This study highlights Syrian refugees' socio-demographic and economic characteristics associated with food insecurity. The results indicate alarming rates of food insecurity (84\%) among Syrian refugees who were recently resettled in Saskatoon and Toronto. Households with total annual incomes less than $\$ 40,000$, and with at least one female family member with a higher educational level were at the highest risk of food insecurity.

The high prevalence of food insecurity observed among Syrian refugees is consistent with other Canadian studies involving newcomers from different regions (Lane et al., 2019; Vahabi et al., 2011). However, our study observed a substantially higher rate of food insecurity among recent Syrian refugees compared to the CCHS national survey, which reported that $15 \%$ of recent immigrants were food insecure (Tarasuk et al., 2016). Many factors may contribute to the variation in results. Refugees' vulnerability to food insecurity may be different from that of immigrants (Lane et al., 2019; Dietitians of Canada, 2016). By combining immigrants and refugees into one group, CCHS results likely underestimated the food insecurity status of refugees. While immigrants choose to immigrate, refugees flee their country and live in disadvantaged conditions in neighbouring countries and in United Nations High Commissioner for Refugees (UNHCR) camps with poor access to healthcare, education and other productive life requirements before resettlement. Upon resettlement, refugees encounter several challenges shared with immigrants; however, refugees' presettlement conditions may add to the burden refugees face and increase their likelihood of experiencing food insecurity (Nunnery \& Dharod, 2017). Given the potential for higher vulnerability of refugees to food insecurity, they need to be identified as a distinct group separate from immigrants, within the CCHS surveys. 


\section{Household food insecurity and associated socio-economic factors}

Another likely interpretation is that the national surveys such as CCHS may underestimate the food insecurity status of recent immigrants, including refugees. The CCHS relies on interviews in one of the two official languages, which may exclude recent immigrants and refugees that are unable to communicate in an official language. Recruiting hard to reach newcomers with the assistance of community partners and using interpreters to conduct interviews in the native language of participants in recent studies, including this study, provided a much more accurate picture of the vulnerability levels (Lane et al., 2019; Vahabi \& Damba, 2013; Vahabiet al., 2011). Given the wide discrepancy in food insecurity rates between these studies and the CCHS, national surveys should consider adopting a linguistically accessible approach to ensure equitable representation of all newcomers.

Findings of this study supports earlier studies that low income is associated with food insecurity (Peterman et al., 2013; Masri \& Srour, 2014; Vahabi et al., 2011). Households with less than $\$ 40,000$ income had higher incidents of food insecurity. As pointed by other studies, poor official language proficiency may explain barriers to employment among refugees. (Vahabi \& Damba, 2013; Vahabi et al., 2011). In addition, difficulties of accreditation of past work experience and educational qualifications were making it difficult for the refugees to get well-paying jobs (Immigration, Refugees and Citizenship Canada, 2016). Although refugees receive social assistance during their first year of residency, lack of savings, low employment opportunities as well as difficulties with finding well-paid jobs may contribute to low income and subsequent food insecurity (Dietitians of Canada, 2016). According to the Rapid Impact Evaluation Report of the Syrian Refugee Initiative, around $69.8 \%$ of GARs claimed that the financial assistance support that they received was not enough to cover basic necessities. However, only $26.1 \%$ of the PSRs made the same claim (Immigration, Refugees and Citizenship Canada, 2016). This may explain our finding that GAR refugees had higher rate of food insecurity. GARs also indicated that 12 months of income support did not give them enough time to overcome language barriers and medical problems they had to integrate into the labour market. Poorer economic integration has been observed among GARs as compared to PSRs in the early years of settlement, possibly due to higher access to social capital among the PSRs (Dhital, 2015). Critically assessing current income supports, as well as providing mentorship or training opportunities to assist recent refugees in finding work in their field of expertise, is imperative to improve their economic success and integration into the new society.

It is reported that the ability to access social support networks may play an important factor in countering food insecurity risks (Dean et al., 2011). The majority of our sample was GAR refugees that may not have benefited from a social support network through cultural or religious organizations. This is different from the situation refugees in PSR category who have often benefitted the support from sponsors (Agrawal \& Zeitouny, 2017). In addition, PSR refugees tend to be professionals and more educated, and thus have higher access to social capital through their sponsors to their community and networking and personal support.

Similar to other studies (Lane et al. 2019), our results indicate that families where women had higher levels of education (those with high schools and/or some postsecondary training) were at higher risk of food insecurity. One might speculate that households with less-educated women maybe resilient and their households were not as food insecure as one would have assumed. This phenomenon may be related to their access to social support networks as families with low educational levels may be more adaptive at building social support network, and using skills that 
do not require high levels education to develop coping strategies to overcome household financial hardship in securing adequate food (Dean \& Sharkey, 2011). It is notable that the majority of families in our study were reliant on welfare disregarding the women's education level. This indicate the perception of food security might be different between the two groups of families. Overall, this finding warrens further investigation on relationship between food insecurity and educational level beyond only the employment status and to consider resilience and coping strategies.

To our knowledge, this is the first study to determine the food security status and associated socio-demographic factors among recently resettled Syrian refugees residing in Saskatoon and Toronto. One strength of this study is that interviews were conducted in participants' native language, (i.e., Arabic), through a validated questionnaire used in Canadian national surveys, resulting in decreased bias and opportunities to compare results with other segments of the Canadian population. Nevertheless, this study has some limitations. The study findings cannot be generalized to the total population of Syrian refugees in Canada because of the challenges with random sampling of recent hard to reach refugees. Furthermore, although purposeful sampling was used, there were challenges with recruiting refugees from different sponsorship categories, while we were able to recruit GAR households who were closely connected to settlement agencies. This study also employed a cross-sectional design, which indicates association rather than causation.

\section{Conclusion}

This study provides new recognition of the high prevalence of food insecurity levels and associated socioeconomic factors among recent Syrian refugees in Toronto and Saskatoon. Syrian refugee households vulnerable to food insecurity were characterized by a low annual income level $(\$ 40,000)$. Families where low educated women had lower risk of food insecurity compared to families with higher educated women. Future in depth investigation of the complex lived realities (including access to social support networks as well as coping strategies) is warranted. The findings suggest the need for programs to enhance household's livelihoods and financial independence. The results also revealed the importance of empowering refugees through oriented language programs according to their low educational level along with a job-specific language training. Furthermore, a comprehensive and more in-depth study of this cohort around several provinces in Canada is important to evaluate their vulnerability to food insecurity in order to provide policy makers with recommendations to ensure the well-being of Syrian refugees in Canada.

\section{Acknowledgement}

HV Led the research team to conceptualize the study, receive funding, administer the project. He also supervised the data collection by graduate students and research personnel, data analyses, writing and editing the paper. LA was mainly involved with data cleaning, processing and analyses, wrote the first draft, and contributed in editing and revisions based on the co-authors comments. SA helped coordinate the data collection in Saskatoon and Toronto, recruited and interviewed some Syrian participants in Saskatoon, translated the questionnaires, and reviewed and edited the first draft. MC led the administration of the project in the Toronto site. All co-authors reviewed the first draft and contributed to editing. 


\section{Household food insecurity and associated socio-economic factors}

We would like to sincerely thank the Syrian refugee families who enthusiastically participated in this project. We are grateful for the refugee settlement agencies that connected us with refugee families. The agencies include Saskatoon Open Door Society, and in Toronto: Poly cultural immigrant and community center, Muslim association of Canada, and the Arab Community Center of Toronto (both Scarborough and Mississauga locations. We also thank Ms. Sindhuja Dasarathi and Ms. Dina Taha, who coordinated data collection in Saskatoon and Toronto, respectively, Ms. Naorin Islam for assisting in data analyses, as well as Dr. Mahasti Khakpour, who enthusiastically assisted in training the research assistants.

\section{Funding Information}

Funding for this project is provided by Social Sciences and Humanities Research Council of Canada (SSHRC) under the initiative of Culture, Migration, and Food Security (CMF) international research group in Vatanparast Nutritional Epidemiology Laboratory.

\section{References}

Agrawal, S., Zeitouny, S. (2017). Settlement Experience of Syrian Refugees in Alberta. University of Alberta: Edmonton, Alberta. Retrieved from https://cms.eas.ualberta.ca/UrbanEnvOb/wp-content/uploads/sites/21/2017/11/SyrianRefugees-final-report-Nov-2017-1.pdf

Canadian Council for Refugees. (2010). Refugees and Immigrants: A glossary | Canadian Council for Refugees. Retrieved March 9, 2020, from https://ccrweb.ca/en/glossary

Dean, W. R., \& Sharkey, J. R. (2011). Food insecurity, social capital and perceived personal disparity in a predominantly rural region of Texas: an individual-level analysis. Social Science \& Medicine, 72(9), 1454-1462.

Dhital, D. (2015). The Economic Outcomes of Government Assisted Refugees, Privately Sponsored Refugees and Asylum Seekers in Canada. University of Ottawa: Ottawa, Canada. Retreived from: https://ruor.uottawa.ca/bitstream/ 10393/32311/1/DIKSHYA,\%20Dikshya\%2020151.pdf

Dietitians of Canada. (2016). Prevalence, Severity and Impact of Household Food Insecurity: A Serious Public Health Issue-Background Paper. Canadian Journal of Dietetic Practice and Research, 77(3), 55. Retrieved from https://www.dietitians.ca/Dietitians-Views/Food-Security/Household-Food-Insecurity.aspx

Drolet, J., Enns, R., Kreitzer, L., \& Mclaughlin, A. (2018). Supporting the resettlement of a Syrian family in Canada: The social work resettlement practice experience of Social Justice Matters. International Social Work, 61(5), 627-633.

Drolet, J., Moorthi, G. (2018). The settlement experiences of Syrian newcomers in Alberta: Social connections and interactions. Canadian Ethnic Studies Journal, 50(2), 101-121.

Fang, T., Sapeha, H., Neil , K., \& Jaunty-Aidamenbor, O. (2017). Syrian Refugee Arrival, Resettlement and Integration in Newfoundland and Labrador (PowerPoint slides). Pathways to Prosperity 2017 National Conference: Canada's Place in the World: Innovation in Immigration Research, Policy, and Practice. Toronto. Retrieved from: p2pcanada.ca/wp-content/blogs.dir/1/files/2017/11/A7-Tony-Fang.pdf

Food and Agriculture Organization of the United Nations. (1996). World Food Summit - Final Report - Part 1. Retrieved from http://www.fao.org/3/w3548e/w3548e00.htm

Ghattas, H., Sassine, A., Seyfert, K., Nord, M., \& Sahyoun, N. (2014). Food insecurity among Iraqi refugees living in Lebanon, 10 years after the invasion of Iraq: data from a household survey. British Journal of Nutrition, 112(1), 7079.

Ghattas, H., Sassine, A., Seyfert, K., Nord, M., \& Sahyoun, N. (2015). Prevalence and Correlates of Food Insecurity among Palestinian Refugees in Lebanon: Data from a Household Survey. PLoS ONE, 10(6), 10.

Government of Canada. (2016). 2016 Annual Report to Parliament on Immigration. Retrieved from Government of Canada: http:/www.cic.gc.ca/english/resources/publications/annual-report-2016/index.asp

Government of Canada. (2018). Key Health Inequalities in Canada: A National Portrait - Executive Summary Canada.ca. Public Health Agency of Canada. Retrieved from https://www.canada.ca/en/public-health/services/ publications/science-research-data/key-health-inequalities-canada-national-portrait-executive-summary.html

Government of Canada. (2018). Syrian Refugees Family Composition Ad Hoc IRCC (Specialized Datasets). Retrieved from Government of Canada: https://open.canada.ca/data/en/dataset/ca243c40-a6d3-4a46-a578-b4fad4369df0 
Gundersen, C., Tarasuk, V., Cheng, J., de Oliveira, C., \& Kurdyak, V. (2018). Food insecurity status and mortality among adults in Ontario, Canada. PLoS ONE, 13(8), e0202642.

Health Canada. (2006). Canadian Community Health Survey Cycle 2.2, Nutrition (2004): A Guide to Accessing and Interpreting the Data. Office of Nutrition Policy and Promotion, Health Products and Food Branch. Ottawa, Ontario: Health Canada. Retrieved May 26, 2020, from Government of Canada: https://www.canada.ca/en/healthcanada/services/food-nutrition/food-nutrition-surveillance/health-nutrition-surveys/canadian-community-healthsurvey-cchs/canadian-community-health-survey-cycle-2-2-nutrition-2004-guide-accessing-interpreting-data-healthca

Health Canada. (2012). The Household Food Security Survey Module (HFSSM). Retrieved from Government of Canada: https://www.canada.ca/en/health-canada/services/food-nutrition/food-nutrition-surveillance/health-nutritionsurveys/canadian-community-health-survey-cchs/household-food-insecurity-canada-overview/household-foodsecurity-survey-module-hfssm-health-nutrition-surveys-health-canada.html

Houle, R. (2019). Results from the 2016 Census: Syrian refugees who resettled in Canada in 2015 and 2016. Retrieved from Statistics Canada: https://www150.statcan.gc.ca/n1/pub/75-006-x/2019001/article/00001-eng.htm

Immigration, Refugees and Citizenship Canada (2017). 2017 Annual report to parliament on immigration. Retrieved September 6, 2020, from https://www.canada.ca/en/immigration-refugees-citizenship/corporate/publicationsmanuals/annual-report-parliament-immigration-2017.html

Immigration, Refugees and Citizenship Canada. (2016). Rapid Impact Evaluation of the Syrian Refugee Initiative. Retrieved from Immigration, Refugees and Citizenship Canada: https://www.canada.ca/en/immigration-refugeescitizenship/corporate/reports-statistics/evaluations/rapid-impact-evaluation-syrian-refugee-initiative.html

Immigration, Refugees and Citizenship Canada. (2016). Syrian Refugees Family Composition - Ad Hoc IRCC (Specialized Datasets).Ottawa, Canada. Retrieved January 1, 2020, from https://open.canada.ca/data/ en/dataset/ca243c40-a6d3-4a46-a578-b4fad4369df0

Jessiman-Perreault, G., \& McIntyre, L. (2017). The household food insecurity gradient and potential reductions in adverse population mental health outcomes in Canadian adults. SSM - Population Health, 3, 464-472. https://doi.org/10.1016/j.ssmph.2017.05.013

Kirkpatrick, S. I., \& Tarasuk, V. (2008). The Journal of Nutrition Community and International Nutrition Food Insecurity Is Associated with Nutrient Inadequacies among Canadian Adults and Adolescents 1-3. J. Nutr (Vol. 138). Retrieved from https://academic.oup.com/jn/article/138/3/604/4670266

Lane, G., Nisbet, C., \& Vatanparast, H. (2019). Food Insecurity and Nutritional Risk among Canadian Newcomer Children in Saskatchewan. Nutrients, 11(8), 1744. https://doi.org/10.3390/nu11081744

Lee, J., Kubik, M. Y., \& Fulkerson, J. A. (2019). Diet Quality and Fruit, Vegetable, and Sugar-Sweetened Beverage Consumption by Household Food Insecurity among 8- to 12-Year-Old Children during Summer Months. Journal of the Academy of Nutrition and Dietetics, 119(10), 1695-1702. https://doi.org/10.1016/j.jand.2019.03.004

Masri, S.; Srour, I. (2014). Assessment of the impact of Syrian refugees in Lebanon and their employment profile. Regional Office for the Arab States. Beirut: International Labour Organization. Retrieved from http://www.ilo.org/ beirut/publications/WCMS_240134/lang--en/index.htm

McKay, F. H., Haines, B. C., \& Dunn, M. (2019). Measuring and Understanding Food Insecurity in Australia: A Systematic Review. International Journal of Environmental Research and Public Health, 16(3), 27.

Men, F., Gundersen, C., Urquia, M. L., \& Tarasuk, V. (2020). Association between household food insecurity and mortality in Canada: A population-based retrospective cohort study. CMAJ, 192(3), E53-E60. https://oi.org/ 10.1503/cmaj. 190385

Moffat, T., Mohammed, C., \& Newbold, K. (2017). Cultural Dimensions of Food Insecurity Among Immigrants and Refugees. Human Organization, 76(1), 15-27.

Nunnery, D. L., \& Dharod, J. M. (2017). Potential determinants of food security among refugees in the U.S.: an examination of pre- and post- resettlement factors. Food Security, 9(1), 163-179.

Nunnery, D., Haldeman, L., Morrison, A., \& Dharod, S. (2015). Food Insecurity and Budgeting Among Liberians in the US: How are They Related to Socio-demographic and Pre-resettlement Characteristics. Journal of Immigrant and Minority Health, 17(2), 506-512.

Peterman, J. N., Wilde, P. E., Silka, L., Bermudez, O. I., \& Rogers, B. L. (2013). Food insecurity among Cambodian refugee women two decades post resettlement. Journal of Immigrant and Minority Health, 15(2), 372-380. https://doi.org/10.1007/s10903-012-9704-5

Statistics Canada. (2018). Canadian Community Health Survey (CCHS) - 2017. Retrieved September 30, 2020, from: https://www23.statcan.gc.ca/imdb/p3Instr.pl?Function=assembleInstr\&a=1\&\&lang=en\&Item_Id=507367 


\section{Household food insecurity and associated socio-economic factors}

Statistics Canada. (2017). Immigration and Ethnocultural Diversity Highlight Tables. Ottawa (ON): Statistics Canada. Retrieved from: https://www12.statcan.gc.ca/census-recensement/2016/dp-pd/hlt-fst/imm/Table.cfm?Lang= E\&T= $11 \& \mathrm{Geo}=00$

Statistics Canada. (2018). 2006 Census questions. Retrieved May 26, 2020, from Statistics Canada: https://www12.statcan.gc.ca/census-recensement/2006/ref/dict/overview-apercu/pop4-eng.cfm

Tarasuk, V., Cheng, J., De Oliveira, C., Dachner, N., Gundersen, C., \& Kurdyak, P. (2015). Association between household food insecurity and annual health care costs. CMAJ, 187(14). https://doi.org/10.1503/cmaj.150234

Tarasuk, V., Fafard St-Germain, A. A., \& Mitchell, A. (2019). Geographic and socio-demographic predictors of household food insecurity in Canada, 2011-12. BMC Public Health, 19(1), 12.

Tarasuk, V.; Mitchell, A.; Dachner, N. (2016). Household food insecurity in Canada, 2014. Toronto: PROOF (Food Insecurity Policy Research). Retrieved August 25, 2020 from PROOF (Food Insecurity Policy Research): https://proof.utoronto.ca/resources/proof-annual-reports/annual-report-2014/

UNHCR. (2018). Global Trends: Forced Displacement in 2017. Retrieved May 24, 2020, from UNHCR: https://www.unhcr.org/globaltrends2017/

Vahabi, M., \& Damba, C. (2013). Perceived barriers in accessing food among recent Latin American immigrants in Toronto. International Journal for Equity in Health, 12(1), 1. https://doi.org/10.1186/1475-9276-12-1

Vahabi, M., Damba, C., Rocha, C., \& Montoya, E. C. (2011). Food insecurity among Latin American recent immigrants in Toronto. Journal of Immigrant and Minority Health, 13(5), 929-939. https://doi.org/10.1007/s10903-010-9384-y 